\title{
Correlation of 2-year SRS-22r and ODI patient-reported outcomes with 5-year patient-reported outcomes after complex spinal fusion: a 5-year single-institution study of 118 patients
}

\author{
Owoicho Adogwa, MD, MPH, Isaac O. Karikari, MD, ${ }^{2}$ Aladine A. Elsamadicy, BE, ${ }^{2}$ \\ Amanda R. Sergesketter, BS, ${ }^{2}$ Diego Galan, BA, ${ }^{2}$ and Keith H. Bridwell, MD ${ }^{3}$
}

'Department of Neurosurgery, Rush University Medical Center, Chicago, Illinois; ${ }^{2}$ Department of Neurosurgery, Duke University Medical Center, Durham, North Carolina; and ${ }^{3}$ Department of Orthopaedic Surgery, Washington University, St. Louis, Missouri

OBJECTIVE Patient-reported outcomes (PROs) are often measured up to 2 years after surgery; however, prospective collection of longitudinal outcomes for 5 years postoperatively can be challenging due to lack of patient follow-up. The aim of this study was to determine whether PROs collected at 2-year follow-up accurately predict long-term PROs 5 years after complex spinal fusion ( $\geq 5$ levels).

METHODS This was an ambispective study of 118 adult patients ( $\geq 18$ years old) undergoing $\geq 5$-level spinal arthrodesis to the sacrum with iliac fixation from January 2002 to December 2011. Patient demographics and radiographic parameters as well as intraoperative variables were collected. PRO instruments (Scoliosis Research Society [SRS]-22r function, self-image, mental health, pain, and Oswestry Disability Index [ODI]) were completed before surgery then at 2 and 5 years after surgery. Primary outcome investigated in this study was the correlation between SRS-22r domains and ODI collected at 2- and 5-year follow-up.

RESULTS Of the 118 patients, 111 patients had baseline PROs, 105 patients had 2-year follow-up data, and 91 patients had 5-year follow-up PRO data with $72 \%$ undergoing revision surgery. The average pre- and postoperative major coronal curve Cobb angles for the cohort were $32.1^{\circ} \pm 23.7^{\circ}$ and $19.8^{\circ} \pm 19.3^{\circ}$, respectively. There was a strong correlation between 2- and 5-year ODI $\left(r^{2}=0.80, p<0.001\right)$ and between 2- and 5-year SRS-22 $r$ domains, including function $\left(r^{2}=\right.$ $0.79, p<0.001)$, self-image $\left(r^{2}=0.82, p<0.001\right)$, mental health $\left(r^{2}=0.77, p<0.001\right)$, and pain $\left(r^{2}=0.79, p<0.001\right)$. Of the PROs, ODI showed the greatest absolute change from baseline to 2- and 5-year follow-up (2-year $\Delta 17.6 \pm 15.9$; 5 -year $\Delta 16.5 \pm 19.9$ ) followed by SRS-22r self-image (2-year $\Delta 1.4 \pm 0.96$; 5 -year $\Delta 1.3 \pm 1.0)$, pain (2-year $\Delta 0.94 \pm$ 0.97 ; 5-year $\Delta 0.80 \pm 1.0$ ), function (2-year $\Delta 0.60 \pm 0.62$; 5-year $\Delta 0.49 \pm 0.79$ ), and mental health (2-year $\Delta 0.49 \pm$ 0.77 ; 5-year $\Delta 0.38 \pm 0.84$ ).

CONCLUSIONS Patient-reported outcomes collected at 2-year follow-up may accurately predict long-term PROs (5year follow-up).

https://thejns.org/doi/abs/10.3171/2018.2.SPINE171142

KEYWORDS deformity correction; patient-reported outcomes; SRS domains; surgical technique

$\mathrm{I}$ $\mathrm{N}$ an era of shifting emphasis toward quantifiable measures of quality of care as determinants of physicianand hospital-level performance, patient-reported outcomes (PROs) have become an increasingly popular tool to assess subjective outcomes after surgery. ${ }^{4,26}$ PROs are especially utilized in spinal surgery, as many spinal deformities have significant implications for patients' perceptions of health and appearance. ${ }^{1,16}$ Correction of complex spinal deformities involving multiple $(\geq 5)$ levels has been shown to produce significant improvements in PROs com-

ABBREVIATIONS CCI = Charlson Comorbidity Index; EBL = estimated blood loss; IQR = interquartile range; LOS = length of stay; MCID = minimum clinically important difference; $\mathrm{ODI}=$ Oswestry Disability Index; PRO = patient-reported outcome; SD = standard deviation; SRS = Scoliosis Research Society; VAS = visual analog scale. SUBMITTED October 18, 2017. ACCEPTED February 8, 2018.

INCLUDE WHEN CITING Published online July 6, 2018; DOI: 10.3171/2018.2.SPINE171142. 
pared to baseline. ${ }^{11,16}$ Combinations of questionnaires, such as the Scoliosis Research Society (SRS)-22r and Oswestry Disability Index (ODI), are among the most popular assessment tools used to measure PROs in spinal deformity patients. ${ }^{13}$ Both the SRS-22r and the ODI have demonstrated effectiveness in accurately reflecting different aspects of patients' perceptions of health, as well as the extent of their perceived improvement after surgery. $8,9,17$ The SRS22r questionnaire measures 5 domains - pain, activity, appearance, mental health, and satisfaction ${ }^{24}$ - whereas the ODI questionnaire evaluates disability in the context of low-back pain. ${ }^{17}$

Although collecting PROs years after surgery provides valuable insight into long-term subjective outcomes, extended follow-up can be challenging due to lack of consistency, missed appointments, and changes in contact information. ${ }^{7,30,32}$ Due to the challenges inherent to the attainment of long-term PROs, previous studies have examined whether the SRS-22r and ODI administered at postoperative follow-up appointments can predict longterm PROs up to 1 year, ${ }^{3,29} 2$ years, ${ }^{2,22}$ and 3 years ${ }^{20}$ after spinal surgery. However, while PROs collected for even more extended time periods after spine surgery remain valuable for predicting long-term outcomes and assessing the effectiveness of surgery, there is a paucity of data on whether 2-year PROs can predict long-term PROs up to 5 years after surgery for deformity correction.

The aim of this study was to determine whether PROs collected at 2-year follow-up accurately predict long-term PROs 5 years after complex spinal fusion ( $\geq 5$ levels).

\section{Methods}

This is an ambispective study (prospectively collected data and retrospectively analyzed) of 118 adult patients ( $\geq$ 18 years old) who underwent $\geq 5$ levels of spinal fusion to the sacrum with iliac fixation between January 2002 and December 2011 at a major academic institution. Institutional review board approval was obtained prior to the initiation of the study. All patients included in the study had 1) available demographic and treatment data and 2) prospectively collected outcomes measures. Of the 118 patients, 111 patients had baseline PROs, 105 patients had 2-year follow-up data, and 91 patients had 5-year followup PRO data. All surgeries were performed by one of 2 fellowship-trained spine surgeons.

Demographic variables evaluated in this study included patient age and Charlson Comorbidity Index (CCI). Intraoperative and postoperative variables include operative time, estimated blood loss (EBL), length of stay (LOS), and median number of complications (with interquartile range $[\mathrm{IQR}])$. Cobb angles, pelvic incidence, pelvic tilt, sagittal balance, and coronal balance were evaluated both preoperatively and postoperatively.

PRO instruments included the SRS-22r self-image, pain, mental health, and disability domains and the ODI. Administered questionnaires were identical and were selfadministered before surgery and then at 2 and 5 years after surgery. The ODI is a self-administered questionnaire assessing back-specific function, with higher scores representing increasing disability or higher pain levels. Values
TABLE 1. Baseline demographic and preoperative variables for the 118 patients included in this study

\begin{tabular}{lc}
\hline \multicolumn{1}{c}{ Variable } & Value \\
\hline Age, mean (years) & $57.8 \pm 13.0$ \\
\hline $\mathrm{CCl}$ & 1 \\
\hline Median & $0-3$ \\
\hline IQR & 27.1 \\
\hline Primary (\%) & 72.9 \\
\hline Revision (\%) & 55.1 \\
\hline 3-column osteotomy $(\%)$ & $32.1 \pm 23.7$ \\
\hline Major coronal curve Cobb, mean $\left(^{\circ}\right)$ & $50.4 \pm 18.0$ \\
\hline Pelvic incidence, mean $\left(^{\circ}\right)$ & $34.6 \pm 9.4$ \\
\hline Pelvic tilt, mean $\left(^{\circ}\right.$ ) & $117.1 \pm 61.7$ \\
\hline Sagittal balance, mean (mm) & $29.7 \pm 23.9$ \\
\hline Coronal balance, mean (mm) & \\
\hline Preop SRS-22r \& ODI scores, mean & $2.4 \pm 0.86$ \\
\hline SRS-22r function & $1.9 \pm 0.74$ \\
\hline SRS-22r self-image & $3.1 \pm 1.0$ \\
\hline SRS-22r mental health & $2.3 \pm 0.87$ \\
\hline SRS-22r pain & $46.8 \pm 17.3$ \\
\hline ODI
\end{tabular}

range from 0 to $100(0-20=$ minimal disability; $21-40$ $=$ moderate disability; $41-60=$ severe disability; $61-80=$ crippled; $81-100=$ bedbound). The SRS-22r is a self-administered questionnaire containing 22 items distributed within 5 domains: self-image, pain, mental health, function, and satisfaction. The score for each domain ranges from 1 to 5 , with higher scores indicating better outcomes. The minimum clinically important difference (MCID) thresholds used were a change of score $\geq 10$ for the ODI and a change of score $\geq 0.4$ for the SRS domains. The primary outcome assessed was the correlation between SRS22r and ODI PROs collected at baseline and at 2-year and 5-year follow-up.

Parametric data were expressed as means \pm standard deviation (SD) and compared using the Student t-test. Nominal data were compared using the chi-square test. Both sample populations met the statistical assumptions that enable the Student t-test and chi-square test to be used. All tests were 2-sided and were statistically significant if the $\mathrm{p}$ value was $<0.05$. Statistical analysis was performed using JMP, version 12 (SAS Institute Inc.).

\section{Results}

One hundred eighteen adult patients who underwent complex spinal fusion involving $\geq 5$ levels were included in this study, with 91 patients having PRO data available from baseline, 2-year, and 5-year assessments. The mean age for patients included was $57.8 \pm 13.0$ years (Table 1 ). Of the 118 patients included in the study, $72.1 \%$ were undergoing revision surgeries (Table 1). The median Charlson Comorbidity Index (CCI) was 1 (IQR 0-3) (Table 1). Before the fusion operation, the average ODI for the cohort was $46.8 \pm 17.3$ and the average scores on SRS-22r 
TABLE 2. Intraoperative and postoperative variables

\begin{tabular}{lc}
\hline \multicolumn{1}{c}{ Variable } & Value \\
\hline Operative time (hours) & $8.6 \pm 2.9$ \\
\hline Estimated blood loss $(\mathrm{ml})$ & $1058.6 \pm 1332.2$ \\
\hline Length of stay (days) & $7.4 \pm 5.5$ \\
\hline No. of complications & 1 \\
\hline Median & $0-3.6$ \\
\hline IQR & $19.8 \pm 19.3$ \\
\hline Major coronal curve Cobb $\left(^{\circ}\right)$ & $58.2 \pm 13.0$ \\
\hline Pelvic incidence $\left(^{\circ}\right)$ & $40.1 \pm 21.1$ \\
\hline Pelvic tilt $\left(^{\circ}\right)$ & $52.4 \pm 42.8$ \\
\hline Sagittal balance $(\mathrm{mm})$ & $20.2 \pm 17.8$ \\
\hline Coronal balance $(\mathrm{mm})$ &
\end{tabular}

Data are presented as mean \pm SD unless otherwise indicated.

domains were as follows: $2.4 \pm 0.86$ for function, $1.9 \pm$ 0.74 for self-image, $3.1 \pm 1.0$ for mental health, and $2.3 \pm$ 0.87 for pain (Table 1$)$.

The mean operative time for the cohort was $8.6 \pm 2.9$ hours, average EBL was $1058.6 \pm 1332.2 \mathrm{ml}$, average length of stay (LOS) was $7.4 \pm 5.5$ days, and the median number of complications was 1 (IQR 0-3.6) (Table 2).

Preoperatively, the average major coronal curve Cobb angle for the cohort was $32.1^{\circ} \pm 23.7^{\circ}$, the average pelvic incidence was $50.4^{\circ} \pm 18.0^{\circ}$, the average pelvic tilt was $34.6^{\circ} \pm 9.4^{\circ}$, the average sagittal balance was $117.1 \pm 61.7$ $\mathrm{mm}$, and the average coronal balance was $29.7 \pm 23.9 \mathrm{~mm}$ (Table 1). After thoracolumbar arthrodesis, the average major coronal curve Cobb angle for the cohort was $19.8^{\circ}$ $\pm 19.3^{\circ}$, the average pelvic incidence was $58.2^{\circ} \pm 13.0^{\circ}$, the average pelvic tilt was $40.1^{\circ} \pm 21.1^{\circ}$, the average sagittal balance was $52.4 \pm 42.8 \mathrm{~mm}$, and the average coronal balance was $20.2 \pm 17.8 \mathrm{~mm}$ (Table 2).

At follow-up, there was a strong correlation between 2- and 5-year ODI scores (2-year ODI $28.1 \pm 17.5$; 5-year ODI $29.2 \pm 22.1 ; \mathrm{r}^{2}=0.80, \mathrm{p}<0.001$ ) (Table 3). There was also a strong correlation between 2 -year and 5-year average SRS-22r scores, including function (2-year $3.1 \pm 1.0$; 5 -year $\left.3.0 \pm 1.1 ; \mathrm{r}^{2}=0.79, \mathrm{p}<0.001\right)$, self-image (2-year 3.4 $\pm 1.1 ; 5$-year $\left.3.2 \pm 1.2 ; \mathrm{r}^{2}=0.0 .82, \mathrm{p}<0.001\right)$, mental health (2-year $3.7 \pm 1.1 ; 5$-year $3.5 \pm 1.1 ; \mathrm{r}^{2}=0.77, \mathrm{p}<0.001$ ), and pain $\left(2\right.$-year $3.3 \pm 1.2 ; 5$-year $\left.3.1 \pm 1.2 ; r^{2}=0.79, p<0.001\right)$ (Table 3).

At 2-year and 5-year follow-up, ODI was decreased and measures of all SRS-22r domains were increased from baseline (Fig. 1). Of the PRO metrics assessed, ODI showed the greatest absolute change from baseline to 2and 5-year follow-up (2-year $\Delta 17.6 \pm 15.9 ; 5$-year $\Delta 16.5 \pm$ 19.9) followed by SRS-22r self-image (2-year $\Delta 1.4 \pm 0.96$; 5 -year $\Delta 1.3 \pm 1.0)$, pain $(2$-year $\Delta 0.94 \pm 0.97$; 5 -year $\Delta$ $0.80 \pm 1.0$ ), function (2-year $\Delta 0.60 \pm 0.62 ; 5$-year $\Delta 0.49$ $\pm 0.79)$, and mental health (2-year $\Delta 0.49 \pm 0.77 ; 5$-year $\Delta$ $0.38 \pm 0.84$ ) (Table 3).

On average, the largest improvement in patient-reported status occurred within the first 2 years of surgery (Fig. 1, Table 4). There was a small deterioration in patientreported status between baseline and the 5-year postop-
TABLE 3. Correlation between 2- and 5-year follow-up PROs

\begin{tabular}{lccccc}
\hline \multicolumn{1}{c}{ Variable } & 2 -Year & 5 -Year & $\mathrm{r}^{2}$ & $95 \% \mathrm{Cl}$ & $\mathrm{p} \mathrm{Value}$ \\
\hline $\begin{array}{c}\text { SRS-22r func- } \\
\text { tion }\end{array}$ & $3.1 \pm 1.0$ & $3.0 \pm 1.1$ & 0.79 & $0.70-0.86$ & $<0.001$ \\
\hline $\begin{array}{c}\text { SRS-22r self- } \\
\text { image }\end{array}$ & $3.4 \pm 1.1$ & $3.2 \pm 1.2$ & 0.82 & $0.73-0.88$ & $<0.001$ \\
\hline $\begin{array}{l}\text { SRS-22r men- } \\
\text { tal health }\end{array}$ & $3.7 \pm 1.1$ & $3.5 \pm 1.1$ & 0.77 & $0.66-0.84$ & $<0.001$ \\
\hline SRS-22r pain & $3.3 \pm 1.2$ & $3.1 \pm 1.2$ & 0.79 & $0.70-0.86$ & $<0.001$ \\
\hline SRS-sS & $3.4 \pm 1.0$ & $3.2 \pm 1.1$ & 0.82 & $0.74-0.88$ & $<0.001$ \\
\hline ODI & $28.1 \pm 17.5$ & $29.2 \pm 22.1$ & 0.80 & $0.71-0.87$ & $<0.001$ \\
\hline
\end{tabular}

SRS-sS = SRS sum score.

Data are presented as mean \pm SD.

erative time point, but this change was not significantly different from the change observed at the 2-year postoperative time point (Tables 4 and 5). The improvement in patient-reported status observed at 2 years appeared to be durable through the 5-year follow-up (Fig. 1, Table 4).

The proportions of patients achieving MCID for each of the PROs at 2 years and at 5 years after surgery are shown in Table 6. Comparison of the proportion values for each time point showed no statistically significant difference for any of the PROs.

\section{Discussion}

In this study, we demonstrate a significant correlation between ODI and SRS-22r PROs collected at 2-year and 5 -year follow-up after complex lumbar fusion.

Despite the high complication rates and complexity of surgery inherent to lumbar fusions involving multiple levels, operative correction of complex adult spinal deformity has been shown to lead to significant improvements in PROs, including overall health and disability. ${ }^{8,24,25,31}$ As a result, PRO questionnaires have become commonplace tools to administer in both the preoperative and postoperative settings to measure subjective outcomes of spinal surgery. The ODI and SRS-22r have emerged as some of the most popular tools to assess improvement in patients' perceptions of health and deformity after surgery for deformity correction. ${ }^{6,9}$

Our current study demonstrates the significant improvement in PROs after correction of complex deformity, as the majority of our cohort reported a sustained and statistically significant reduction from baseline in ODI, as well as improvement in all self-assessment domains of the SRS-22r up to 5 years after surgery. More than half of our cohort had very complex revision pathology, with major sagittal imbalance. The surgical effectiveness of spinal surgery in leading to significant and sustained improvements in patient-reported disability and overall outcomes has been previously reported..$^{2,8,9,16,18}$ In our study, we observed the greatest magnitude of change in baseline to follow-up ODI; on the level of the individual SRS-22r domains, our cohort showed the greatest improvement from baseline in the self-image domain, with function, pain, and mental health showing less but still substantial and sig- 


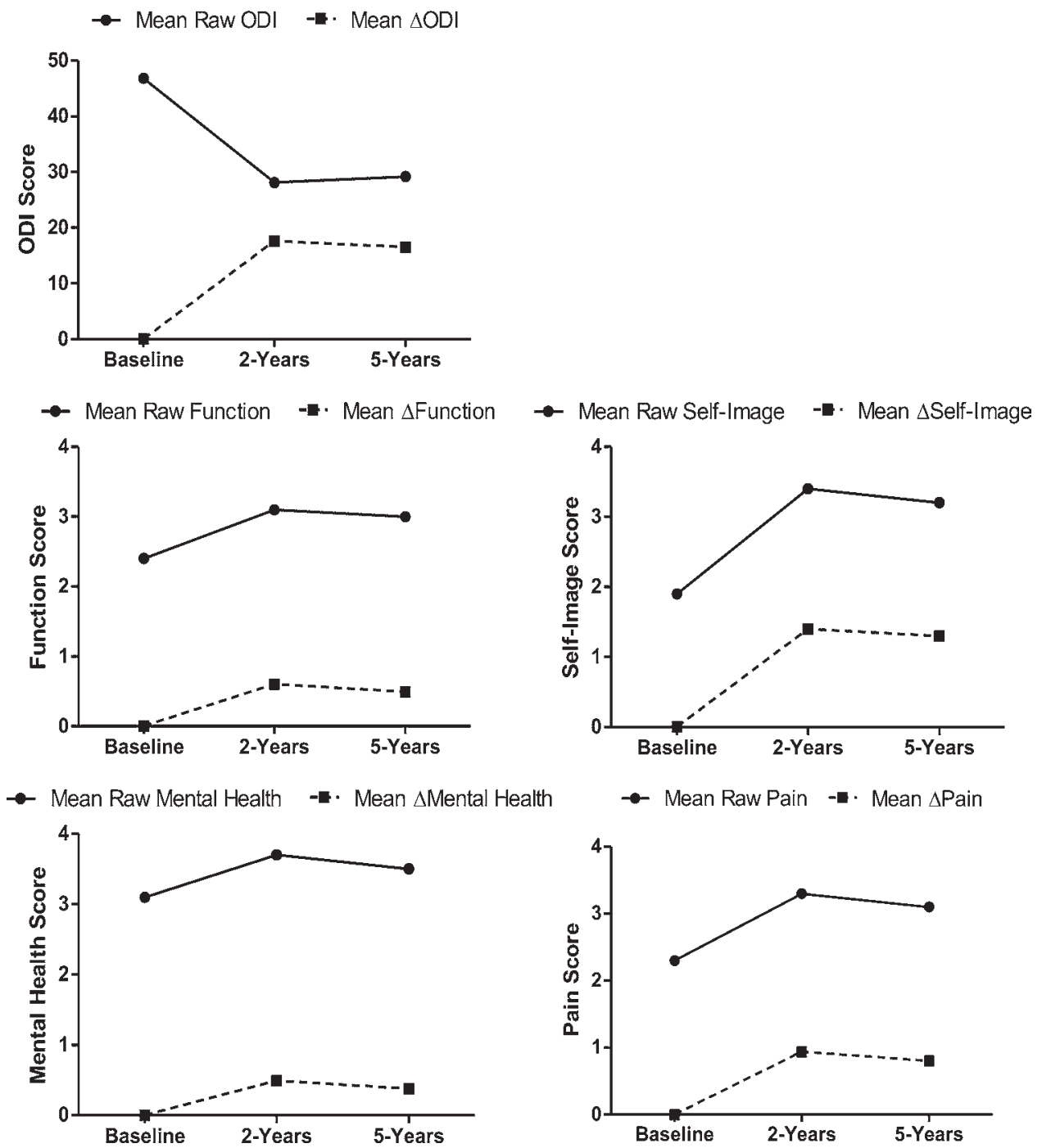

FIG. 1. SRS-22r and ODI scores from baseline to 2 and 5 years after complex spinal fusion operations.

nificant improvement from baseline. The finding that selfimage may be subject to the greatest benefit of all SRS-22r domains after correction of complex deformities has been previously reported. Asher et al. demonstrated the greatest sustained improvement in self-image compared to the other SRS-22r domains in a prospective evaluation of 58 scoliosis patients. ${ }^{5}$ Similarly, in a multicenter, prospective

TABLE 4. Absolute changes in PROs with time

\begin{tabular}{lccc}
\hline \multicolumn{1}{c}{ Variable } & $\begin{array}{c}\Delta \text { 2-Year }- \\
\text { Baseline }\end{array}$ & $\begin{array}{c}\Delta 5 \text {-Year }- \\
\text { Baseline }\end{array}$ & p Value \\
\hline SRS-22r function & $0.60 \pm 0.62$ & $0.49 \pm 0.79$ & 0.270 \\
\hline SRS-22r self-image & $1.4 \pm 0.96$ & $1.3 \pm 1.0$ & 0.758 \\
\hline SRS-22r mental health & $0.49 \pm 0.77$ & $0.38 \pm 0.84$ & 0.353 \\
\hline SRS-22r pain & $0.94 \pm 0.97$ & $0.80 \pm 1.0$ & 0.295 \\
\hline SRS-sS & $0.85 \pm 0.65$ & $0.74 \pm 0.74$ & 0.211 \\
\hline ODI & $17.6 \pm 15.9$ & $16.5 \pm 19.9$ & 0.665 \\
\hline
\end{tabular}

Data are presented as mean \pm SD. study of adult scoliosis patients conducted by Bridwell et al., SRS-22r self-image showed the greatest improvement at 1 - and 2-year follow-up after surgery. ${ }^{8}$ Other studies have reported substantial improvements in patient perceptions of disability as evidenced by significant reductions in ODI after spinal fusion. ${ }^{10,12,15,18,21}$ Due to this potential for significant improvement in both perceptions of disability and self-image, longitudinal assessment of PROs in spinal deformity patients, especially in those undergoing complex fusions, is important in the evaluation of overall surgical outcomes.

Collecting PROs at multiple follow-ups after spinal surgery is important, as patients continue to experience significant changes in healthcare quality-of-life measures owing to their deformity correction up to a year after surgery. Previous studies have reported significant differences in 12-month PROs compared to data collected immediately after spinal surgery. ${ }^{2,19}$ While 12 months has been suggested to be the minimum time period necessary to assess improvement after surgery, ${ }^{2}$ studies have also reported further improvements in PROs, including visual 
TABLE 5. Absolute changes in PROs from 2 to 5 years after surgery and percent deterioration at 5 years

\begin{tabular}{lcc}
\hline \multicolumn{1}{c}{ Variables } & $\Delta$ 5-Year -2 -Year* & $\%$ Deterioration \\
\hline SRS-22r function & $0.09 \pm 0.69$ & -9.3 \\
\hline SRS-22r self-image & $0.05 \pm 0.72$ & -5.2 \\
\hline SRS-22r mental health & $0.09 \pm 0.81$ & -6.4 \\
\hline SRS-22r pain & $0.13 \pm 0.80$ & -18.3 \\
\hline SRS-SS & $0.09 \pm 0.64$ & -1.1 \\
\hline ODI & $0.44 \pm 12.8$ & -5.6 \\
\hline
\end{tabular}

${ }^{*}$ Mean \pm SD

analog scale (VAS) and ODI scores, up to 24 months after spinal fusions. ${ }^{18}$ In a study of 43 patients undergoing posterior fusion with decompression with prospectively collected PROs, Farrokhi et al. found that ODI scores, which averaged 72.18 preoperatively, decreased to an average of 47.81 at 12 months after surgery and decreased further to an average of 15.53 at 24 months' follow-up..$^{18}$ Similarly, in another study of SRS-22 and ODI scores in 170 adult spinal deformity patients, Yoshida et al. reported continued improvement in PRO measures between 1 year and 2 years postoperatively. ${ }^{33}$ Therefore, measuring PROs up to 2 years after surgery may be beneficial in predicting longterm outcomes of deformity correction.

Despite the importance of assessing long-term subjective patient outcomes, loss to follow-up commonly limits surgeons' abilities to collect longitudinal PRO data. ${ }^{7}$ In fact, rates of loss to follow-up after deformity correction have been reported to range from $15 \%$ to $20 \%{ }^{30,32}$ Younger age and preoperative employment have been linked to lack of follow-up after spine surgery. ${ }^{30}$ Solberg et al. examined PROs in patients who were followed up regularly at clinic visits compared to those who were lost to follow-up 2 years after deformity correction. While PROs collected in both groups were reported to be similar, the study suggested that assessment of overall clinical outcomes from PROs at follow-up might be confounded by exclusion of patients who do not return for follow-up visits. ${ }^{32}$ Specifically, patients who elect to return to the clinic may report better outcomes than the patients who elect to not return. The importance of minimizing loss to follow-up for the validity of longitudinal prospective studies has been emphasized across the literature. ${ }^{14,23,28}$ Using effective approaches to disseminate reliable assessments and identifying optimal follow-up time frames to increase retention should reduce patient loss to follow-up.

While some studies have pursued alternative methods to ensure long-term PRO collection, other studies have examined the ability of PROs collected shortly after surgery to predict long-term subjective outcomes. In spinal surgery, the utility of early postoperative PROs to predict long-term SRS-22r and ODI scores has been previously described..$^{2,3,20,22,29}$ In a study of 84 adult spinal deformity patients with ODI and SRS-22r scores collected in the preoperative setting and at 6-week, 1-year, and 3-year follow-up, Jain et al. found that improvements during the 1st postoperative year could be used to accurately predict 3-year PROs. ${ }^{20}$ In a follow-up study of 969 spinal deformi-
TABLE 6. Proportion of patients attaining MCID in PROs at 2 and 5 years after surgery

\begin{tabular}{lccc}
\hline \multicolumn{1}{c}{ Variable } & 2-Year (\%) & 5-Year (\%) & p Value \\
\hline SRS-22r function & 71.7 & 69.1 & 0.693 \\
\hline SRS-22r self-image & 89.6 & 84.0 & 0.242 \\
\hline SRS-22r mental health & 60.6 & 65.6 & 0.467 \\
\hline SRS-22r pain & 74.5 & 70.2 & 0.495 \\
\hline ODI & 70.5 & 71.1 & 0.923 \\
\hline
\end{tabular}

ty patients, Adogwa et al. reported a significant correlation between 1- and 2-year ODI, 36-Item Short-Form Health Survey (SF-36) Physical Component Summary score, and VAS back pain and leg pain. ${ }^{2}$ In this study, patients who achieved MCID at 12-month follow-up were more likely to report improvement at 24-month follow-up, suggesting that 1-year follow-up was a sufficient time period to predict outcomes after deformity correction. ${ }^{2}$ Analogously, our study demonstrated that 2-year SRS-22r domains and ODI reliably correlate with PROs measured at 5-year follow-up after deformity correction.

Interestingly, questionnaires completed in the first few months after spinal surgery have demonstrated little correlation with long-term PROs. Both Asher et al. and Parker et al. examined the correlation of 3-month with 12-month PROs after spinal surgery and found that the 3-month ODI, 3,29 numeric rating scale (NRS), 12-Item Short-Form Health Survey (SF-12), EQ-5D, or Zung Self-Rating Depression Scale ${ }^{29}$ did not reliably predict 12 -month measures at the individual patient level. This lack of predictive power likely stems from patients seeing continued improvement throughout the 1st year after surgery. In a retrospective review of 1803 consecutive patients undergoing spine surgery, McGirt et al. reported the greatest improvement in all measured PROs (ODI, EQ-5D, and VAS back and leg pain) in the 1st postoperative year. ${ }^{27}$ Moreover, in an evaluation of PROs collected up to 3 years postoperatively, Jain et al. reported the most clinically significant improvement from 6-week to 1-year follow-up after surgery. ${ }^{20}$ Clearly, owing to continued improvement in the immediate postoperative setting up to 1 year after surgery, collection of PROs must occur for a minimum amount of time to accurately predict long-term subjective outcomes. Based on these studies' findings, as well as our own, we suggest prospective collection of PROs up to 2 years after surgery to optimize prediction of long-term (5-year or longer) subjective outcomes.

There are limitations to this study, with implications for its interpretation. First, although pre- and perioperative variables were prospectively recorded into the study registry at the time of surgery, these variables were retrospectively analyzed for the purposes of this study and, accordingly, are subject to the drawbacks associated with all retrospective reviews. Second, our study group represented a mixed patient population, consisting of patients who were undergoing primary and revision operations, as well as operations with and without osteotomies, which may have implications on our overall results. Third, our study did not measure or account for patients who were lost to follow-up, and lack of inclusion of these patients' 
outcomes could have affected our conclusions. Furthermore, data on specific complications, such as symptomatic proximal junctional kyphosis and pseudoarthrosis, were not prospectively collected and may have implications for our results. Nonetheless, our loss to follow-up at 2 and 5 years after surgery was quite small, similar to that in other reported series. Finally, our results showing overall improvement in PRO measures are based only on data collected at 2 years and 5 years after surgery and are not reflective of PROs in the immediate postoperative setting. Despite these limitations, we demonstrate the utility of 2-year SRS-22r and ODI scores to predict 5-year PROs after complex spinal fusion.

\section{Conclusions}

Patient-reported outcomes collected at 2-year followup may accurately predict long-term PROs (5-year follow-up).

\section{References}

1. Acaroğlu RE, Dede Ö, Pellisé F, Güler UO, Domingo-Sàbat M, Alanay A, et al: Adult spinal deformity: a very heterogeneous population of patients with different needs. Acta Orthop Traumatol Turc 50:57-62, 2016

2. Adogwa O, Elsamadicy AA, Han JL, Cheng J, Karikari I, Bagley CA: Do measures of surgical effectiveness at 1 year after lumbar spine surgery accurately predict 2-year outcomes? J Neurosurg Spine 25:689-696, 2016

3. Asher AL, Chotai S, Devin CJ, Speroff T, Harrell FE Jr, Nian H, et al: Inadequacy of 3-month Oswestry Disability Index outcome for assessing individual longer-term patient experience after lumbar spine surgery. J Neurosurg Spine 25:170-180, 2016

4. Asher AL, Parker SL, Rolston JD, Selden NR, McGirt MJ: Using clinical registries to improve the quality of neurosurgical care. Neurosurg Clin N Am 26:253-263, ix-x, 2015

5. Asher M, Min Lai S, Burton D, Manna B: Scoliosis Research Society-22 patient questionnaire: responsiveness to change associated with surgical treatment. Spine (Phila Pa 1976) 28:70-73, 2003

6. Berven S, Deviren V, Demir-Deviren S, Hu SS, Bradford DS: Studies in the modified Scoliosis Research Society Outcomes Instrument in adults: validation, reliability, and discriminatory capacity. Spine (Phila Pa 1976) 28:2164-2169, 2003

7. Bokshan SL, Godzik J, Dalton J, Jaffe J, Lenke LG, Kelly MP: Reliability of the revised Scoliosis Research Society-22 and Oswestry Disability Index (ODI) questionnaires in adult spinal deformity when administered by telephone. Spine $\mathbf{J}$ 16:1042-1046, 2016

8. Bridwell KH, Berven S, Glassman S, Hamill C, Horton WC III, Lenke LG, et al: Is the SRS-22 instrument responsive to change in adult scoliosis patients having primary spinal deformity surgery? Spine (Phila Pa 1976) 32:2220-2225, 2007

9. Bridwell KH, Cats-Baril W, Harrast J, Berven S, Glassman S, Farcy JP, et al: The validity of the SRS-22 instrument in an adult spinal deformity population compared with the Oswestry and SF-12: a study of response distribution, concurrent validity, internal consistency, and reliability. Spine (Phila Pa 1976) 30:455-461, 2005

10. Cheng X, Zhang K, Sun X, Zhao C, Li H, Ni B, et al: Clinical and radiographic outcomes of bilateral decompression via a unilateral approach with transforaminal lumbar interbody fusion for degenerative lumbar spondylolisthesis with stenosis. Spine J 17:1127-1133, 2017

11. Crawford CH III, Carreon LY, Bridwell KH, Glassman SD:
Long fusions to the sacrum in elderly patients with spinal deformity. Eur Spine J 21:2165-2169, 2012

12. Crawford CH III, Glassman SD, Mummaneni PV, Knightly JJ, Asher AL: Back pain improvement after decompression without fusion or stabilization in patients with lumbar spinal stenosis and clinically significant preoperative back pain. J Neurosurg Spine 25:596-601, 2016

13. Cutler HS, Guzman JZ, Al Maaieh M, Connolly J, Skovrlj B, Cho SK: Patient reported outcomes in adult spinal deformity surgery: a bibliometric analysis. Spine Deform 3:312-317, 2015

14. Dettori JR: Loss to follow-up. Evid Based Spine Care J 2:7-10, 2011

15. Donnarumma P, Tarantino R, Nigro L, Rullo M, Messina D, Diacinti D, et al: Decompression versus decompression and fusion for degenerative lumbar stenosis: analysis of the factors influencing the outcome of back pain and disability. $\mathbf{J}$ Spine Surg 2:52-58, 2016

16. Elsamadicy AA, Adogwa O, Sergesketter A, Behrens S, Hobbs $\mathrm{C}$, Bridwell $\mathrm{KH}$, et al: Impact of age on change in selfimage 5 years after complex spinal fusion ( $\geq 5$ levels). World Neurosurg 97:112-116, 2017

17. Fairbank JC, Couper J, Davies JB, O'Brien JP: The Oswestry low back pain disability questionnaire. Physiotherapy 66:271-273, 1980

18. Farrokhi MR, Jamali M, Gholami M, Farrokhi F, Hosseini K: Clinical and radiological outcomes after decompression and posterior fusion in patients with degenerative scoliosis. Br J Neurosurg 31:514-525, 2017

19. Glassman SD, Copay AG, Berven SH, Polly DW, Subach BR, Carreon LY: Defining substantial clinical benefit following lumbar spine arthrodesis. J Bone Joint Surg Am 90:18391847,2008

20. Jain A, Kebaish KM, Sciubba DM, Hassanzadeh H, Scheer JK, Neuman BJ, et al: Early patient-reported outcomes predict 3-year outcomes in operatively treated patients with adult spinal deformity. World Neurosurg 102:258-262, 2017

21. Joseph JR, Farooqui Z, Smith BW, Kahn EN, Liu X, La Marca F, et al: Does clinical improvement of symptomatic degenerative lumbar disease impact obesity? J Neurosurg Spine 26:705-708, 2017

22. Kim EJ, Chotai S, Archer KR, Bydon M, Asher AL, Devin CJ: Need for two-year patient-reported outcomes score for lumbar spine surgery is procedure-specific: analysis from a prospective longitudinal spine registry. Spine (Phila Pa 1976) 42:1331-1338, 2017

23. Kristman V, Manno M, Côté P: Loss to follow-up in cohort studies: how much is too much? Eur J Epidemiol 19:751760,2004

24. Lai SM, Asher MA, Burton DC, Carlson BB: Identification of Scoliosis Research Society-22r Health-Related Quality of Life questionnaire domains using factor analysis methodology. Spine (Phila Pa 1976) 35:1236-1240, 2010

25. Lee JS, Lee DH, Suh KT, Kim JI, Lim JM, Goh TS: Validation of the Korean version of the Scoliosis Research Society-22 questionnaire. Eur Spine J 20:1751-1756, 2011

26. McGirt MJ, Parker SL, Asher AL, Norvell D, Sherry N, Devin CJ: Role of prospective registries in defining the value and effectiveness of spine care. Spine (Phila Pa 1976) 39 (22 Suppl 1):S117-S128, 2014

27. McGirt MJ, Sivaganesan A, Asher AL, Devin CJ: Prediction model for outcome after low-back surgery: individualized likelihood of complication, hospital readmission, return to work, and 12-month improvement in functional disability. Neurosurg Focus 39(6):E13, 2015

28. Murray DW, Britton AR, Bulstrode CJ: Loss to follow-up matters. J Bone Joint Surg Br 79:254-257, 1997

29. Parker SL, Asher AL, Godil SS, Devin CJ, McGirt MJ: Patient-reported outcomes 3 months after spine surgery: is 
it an accurate predictor of 12-month outcome in real-world registry platforms? Neurosurg Focus 39(6):E17, 2015

30. Sielatycki JA, Parker SL, Godil SS, McGirt MJ, Devin CJ: Do patient demographics and patient-reported outcomes predict 12-month loss to follow-up after spine surgery? Spine (Phila Pa 1976) 40:1934-1940, 2015

31. Smith JS, Shaffrey CI, Lafage V, Schwab F, Scheer JK, Protopsaltis T, et al: Comparison of best versus worst clinical outcomes for adult spinal deformity surgery: a retrospective review of a prospectively collected, multicenter database with 2-year follow-up. J Neurosurg Spine 23:349-359, 2015

32. Solberg TK, Sørlie A, Sjaavik K, Nygaard OP, Ingebrigtsen $\mathrm{T}$ : Would loss to follow-up bias the outcome evaluation of patients operated for degenerative disorders of the lumbar spine? Acta Orthop 82:56-63, 2011

33. Yoshida G, Boissiere L, Larrieu D, Bourghli A, Vital JM, Gille $\mathrm{O}$, et al: Advantages and disadvantages of adult spinal deformity surgery and its impact on health-related quality of life. Spine (Phila Pa 1976) 42:411-419, 2017

\section{Disclosures}

Dr. Karikari reports a consultant relationship with NuVasive. Dr.
Bridwell reports receipt of royalties from Wolters Kluwer for The Textbook of Spinal Surgery, 1st, 2nd, and 3rd editions.

\section{Author Contributions}

Conception and design: Karikari, Adogwa, Elsamadicy. Acquisition of data: Karikari. Analysis and interpretation of data: Adogwa, Elsamadicy, Sergesketter, Bridwell. Drafting the article: Adogwa, Elsamadicy, Sergesketter, Galan. Critically revising the article: all authors. Reviewed submitted version of manuscript: all authors. Approved the final version of the manuscript on behalf of all authors: Karikari. Statistical analysis: Adogwa, Elsamadicy. Study supervision: Karikari, Bridwell.

\section{Correspondence}

Isaac O. Karikari: Duke University Medical Center, Durham, NC. isaac.karikari@duke.edu. 